\title{
Transport of Chloride Ions Evaluation through Modulated Concrete Microstructures
}

\begin{abstract}
By Batric Pesic*
It is known that the properties of concrete, including the transport of moisture, depend on its microstructure, which can be modulated by chemical and mineral additives, termed as admixtures. In the previous study, the effect of admixtures, such as glycerol as a nanoviscosity modifier, was evaluated indirectly by measuring the corrosion rate of reinforcement steel. However, it was found that this method (corrosion) could be biased due to the effects of admixtures on corrosion inhibition per se. Therefore, there was a need to evaluate the concrete permeability by direct transport through its matrix. This was done in a new experimental design, which allows direct measurement of chloride concentration change with time. A concrete with particular admixture, and of disks geometry, separates two compartments. A ponding compartment serves as a supplier of chloride ions, which upon transport through the concrete matrix are received by a pure water compartment. Chloride concentration in initially pure water compartment is measured with time using ion chromatography.
\end{abstract}

Keywords: $\mathrm{Cl}$ concentration profile, Concrete permeability, Glycerol admixture, Rebar corrosion, Nano-silica admixture.

\section{Introduction}

Concrete is a composite construction material made primarily of Portland cement, coarse and fine aggregates, and water. Chemical or mineral additives are added to modify the properties of concrete. The reactions of cement (primarily calcium oxide and silica) with water, called hydrations, are most important in defining the overall properties of concrete. Although concrete has been in use for millennia, the understanding of hydration mechanisms and properties of hydration products has emerged only in the last several decades. The mechanisms of hydration, as the most critical step in concrete hardening, are explained in numerous articles such as those by Bentz et al. (2016a), Bullard et al. (2011), and Stark et al. (2011).

All properties of concrete depend on its microstructure. Durability of concrete in particular depends on the transport properties of concrete. Thermal cracking (Chala and R., 2015) results from high internal temperature gradient, which depends on the rate of heat conduction in concrete (Liu et al., 2016). Dryingshrinkage cracking is caused by high internal moisture gradient (Cortas et al., 2014), governing further moisture transport in concrete. Corrosion of reinforcement bars is due to high chloride concentration in the pore solution of the cement paste (Hansson et al., 2012), and the decrease of $\mathrm{pH}$, due to carbonation reactions with transported $\mathrm{CO}_{2}$ (Lee, et al., 2013). For concrete

${ }^{*}$ Professor, University of Idaho, USA. 
structures in cold regions, freeze/thaw resistance of concrete (Skripkiūnas et al., 2013) is especially important, as the undesired air entrained in concrete will lead to damage by formation of ice in the internal pores.

This work focuses on the study of moisture transport properties (permeability) of concrete. Therefore, one of the main efforts will be to focus on the improvement of transport properties of concrete in order to prolong service life of concrete structures. The other important effort is to improve the measurement techniques for transport properties of concrete, without doubt a challenging task because mass transfer in concrete is a very slow process.

There are two approaches toward the reduction of permeability of concrete to moisture and associated ions, like chloride. One approach is to use the nanoviscosity modifiers to increase the viscosity of liquid in the pores of cement paste, left half of the Figure 1, and the second approach is to shrink the diameter of conductive pores, right half of the Figure 1, by nano and micro silica concrete pore fillers.

Figure 1. The Schematics of the Conceptual Approach towards the Reduction of Permeability of Moisture in Concrete, Pesic (2014)

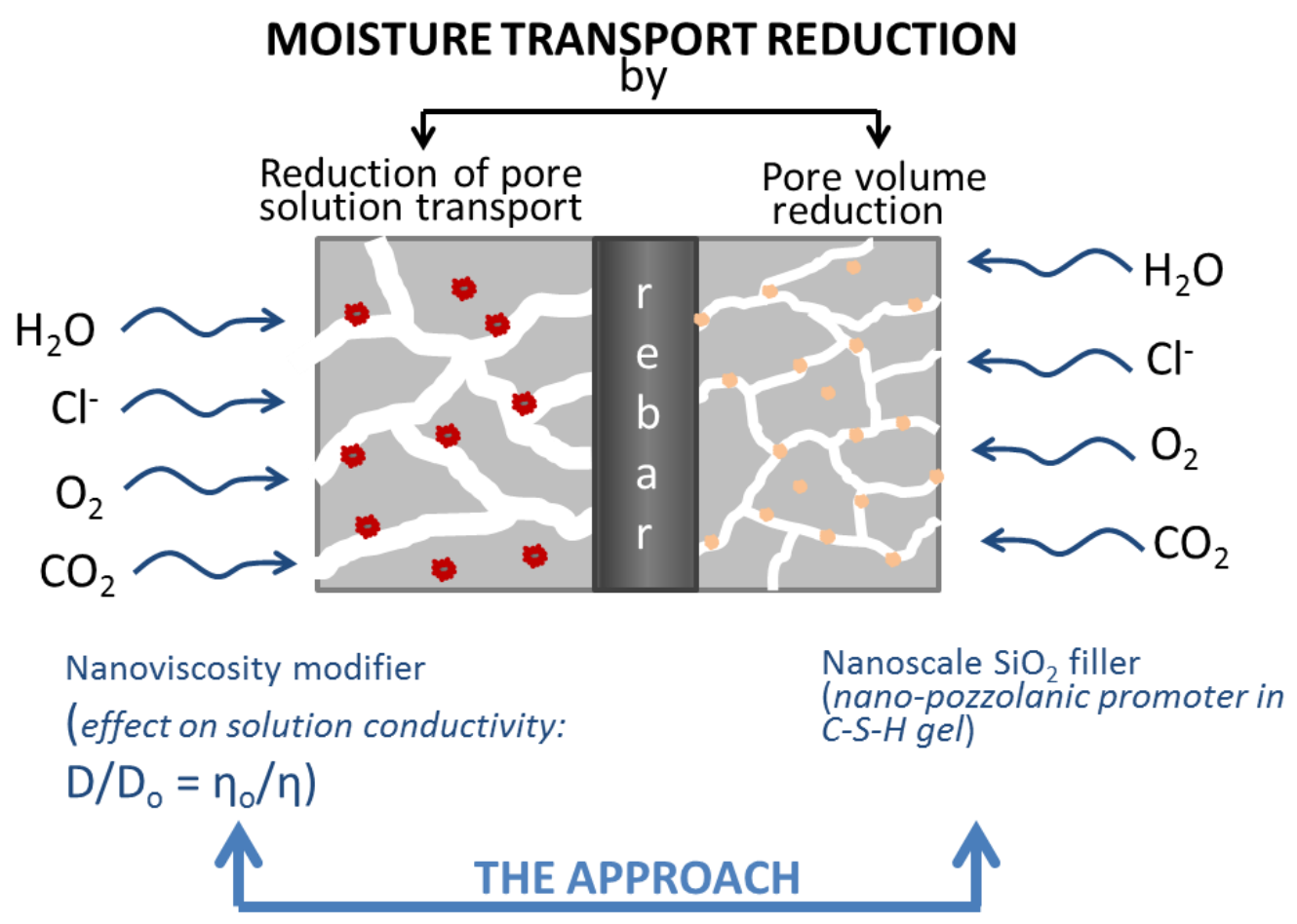

The use of nanoviscosity modifier concept was implemented on the basis of work by Bentz et al. (2008, 2010), who have clearly shown the relationship between viscosity enhancers and solution conductivity, equation (1):

$\mathrm{D} / \mathrm{Do}=\eta_{\mathrm{o}} / \eta$ 
where, D and Do, $\eta, \eta_{\mathrm{o}}$ are diffusion, self-diffusion coefficients, viscosity, and bulk viscosity, respectively. It was found, however, that the above equation holds only for solutions containing the smaller nono-sized additives. For example, cellulose ether and xanthum gum, although measurable viscosity enhancers, have no effect on solution conductivity. Contrary to this, nanosized molecules, such as glycerol (1nm in size) and polyethylene glycol (PEG 400, less than $20 \mathrm{~nm}$ ), by doubling the viscosity reduce the diffusivity of conductive species, thus doubling the life of concrete structures (Bentz et al., 2009; Magniont et al., 2010).

The nanoviscosity modifiers and silica based pore fillers are termed as cement admixtures. They are different from classified rock additives that are called aggregates. Regarding the nano and micro silica role in modulating the concrete properties can be found in the review articles by Aggarwal et al. (2015), Sing et al. (2013), and an article by Ganesh et al. (2016).

Once the approach to the reduction of concrete permeability to moisture, and the containing ions, is delineated, the next requirement is the adoption of appropriate methodology for characterization of permeability as a function of structural changes in concrete. In this regard, the permeability of concrete to moisture can be divided into direct and indirect methods. In direct methods of measurement the typical approach is to analytically measure the concentration of chloride ions that have penetrated concrete, or passed through concrete. In indirect measurement methods, the extent of corrosion of embedded reinforcement steel is used as indicator of the concrete permeability to moisture and associated chloride ions. This is because corrosion does require the moisture as the conduit between the corrosion electrochemical couples, and because chloride ion is the most responsible for pitting, a well-known type of localized corrosion.

In this work, most of the data will reflect the effect of admixtures and aggregates on permeability of concrete. Glycerol is the main admixture representative of nanoviscosity modifiers, while the silica based pore fillers are represented with fumed silica, colloidal silica and micro silica. Among the aggregates that have been studied are silica rock, river rock, and crushed pyrex (borosilicate glass). The procedures and results from the direct measurement methods will be discussed the most. Some data from the indirect, i.e. corrosion, measurements will be presented as well, in details sufficient to prove the concept.

\section{Experimental}

\section{Concrete Sample Preparation}

The concrete specimens are being prepared from Pozzolanic Portland Cement (PPC) mixture sieved through No.12 mesh sieve. The chemical compositions of PPC cement is shown in Table 1. The admixtures, glycerol, or nanosilica, were added to the cement and mixed well before addition of aggregate (quartz silica particles, Lane Mountain LM \#16, Valley, WA, USA). Silica admixtures were represented by silica fume, colloidal silica and micro 
silica. The weight percent of admixtures studied was $0.5 \%, 1.0 \%$ and $2.0 \%$ weight percent with respect to Portland cement component. After addition of $40 \mathrm{wt} \%$ of deionized water to cement, mixing was done to produce a paste with uniform distribution of aggregates. The prepared concrete paste was poured into PVC molds of desired shape geometry and kept at room temperature for 28 days for standard curing. The curing is done in a home-made humidifying chamber, Figure 2.

Table 1. Chemical Composition of PPC Cement

\begin{tabular}{llllllll}
\hline Oxides & $\mathrm{SiO}_{2}$ & $\mathrm{Al}_{2} \mathrm{O}_{3}$ & $\mathrm{Fe}_{2} \mathrm{O}_{3}$ & $\mathrm{CaO}$ & $\mathrm{MgO}$ & $\mathrm{SO}_{3}$ & Fly ash \\
\hline PPC $(\%)$ & $28-32$ & $7.0-1.0$ & $4.9-6.0$ & $41-43$ & $1.0-2.0$ & $2.4-2.8$ & $3.0-3.5$ \\
\hline
\end{tabular}

Figure 2. The Concrete Specimens in the Home-made Humidifying Chamber Stored for Curing for 28 Days. After Curing the Samples were immersed into 3.5\% NaCl Solution for Chloride Sorption. When Sufficient Time (about 560 Days) of Sorption has Passed Concrete Blocks were drilled for Sample Collection and Chloride Analysis with Depth

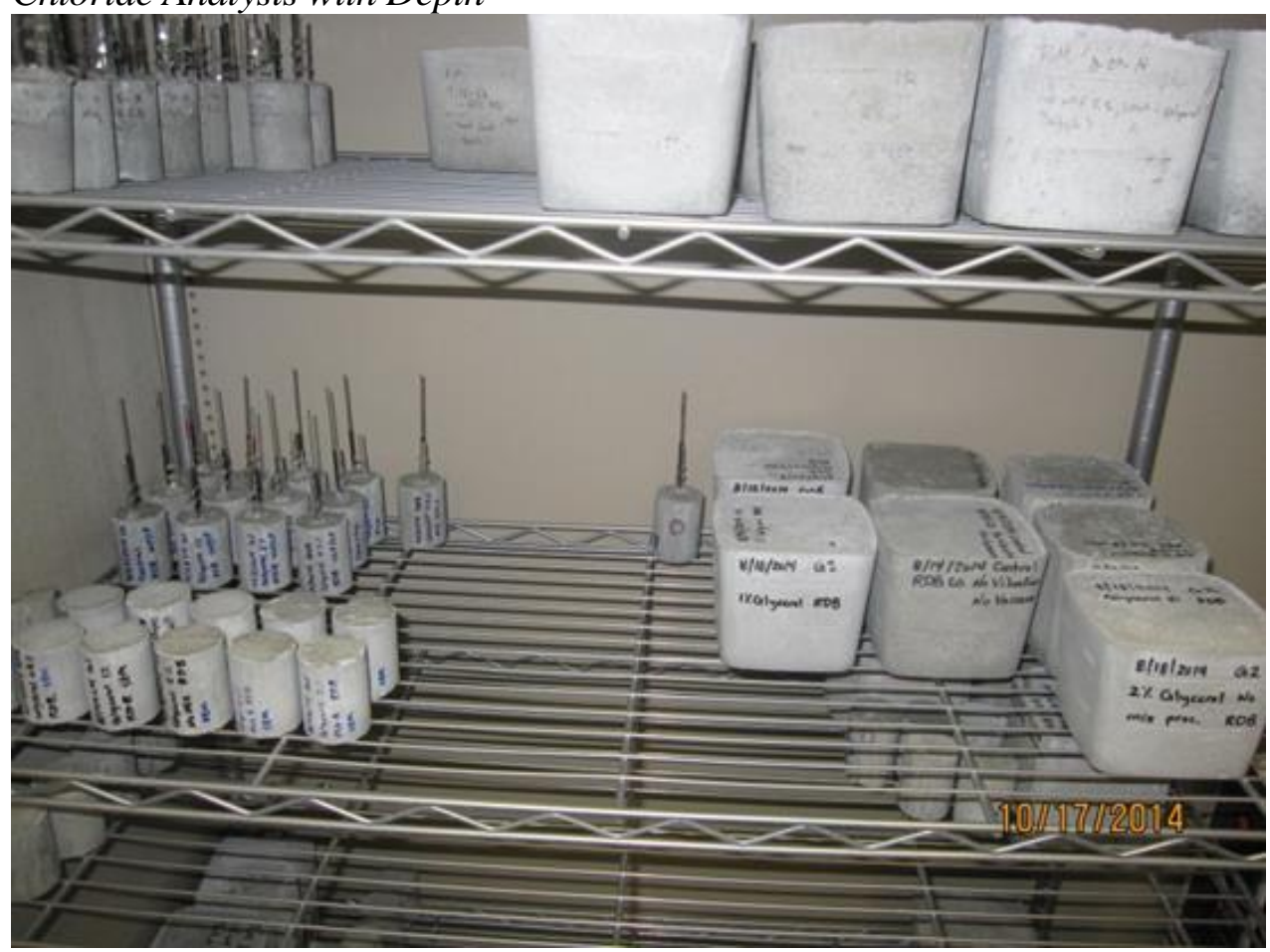

Chloride Permeability Measurement Methods

\section{$\underline{\text { Direct Measurement Methods }}$}

Here the concrete specimens are immersed in chloride containing solution and permeability to chloride ions measured by two methods. In one method a block of concrete is immersed in $3.5 \% \mathrm{NaCl}$ solution for extended period of time, about 2-years, to allow sorption of moisture together with chloride 
containing ions. Subsequently, the concrete block is withdrawn from solution, quickly rinsed with deionized water, dried with paper towel, and finally air dried for several days. Upon drying, the samples of concrete from the various depths are produced by diamond drilling. The powdered samples, collected from a particular depth, are subsequently dissolved in deionized water for analysis on chloride by ion chromatography.

The second method for measuring the permeability of concrete to chloride ions is called the tube method. In this method, the concrete samples are prepared of cylindrical geometry. Upon curing, the concrete cylinders are cut by wafering blades into $1-\mathrm{cm}$ thick disks. The samples then are affixed by epoxy adhesive to the end of the plastic tube. The plastic tube, filled with $3.5 \%$ $\mathrm{NaCl}$ solution, together with an affixed concrete disk, is immersed in deionized water in a jar. In this design, the concrete disk serves as the separator between two aqueous phases, the supplier of chloride ions and the receiving phase of chloride ions. The schematic presentation of this setup is given in Figure 3. Water samples were withdrawn in particular time intervals for the analysis of chloride ions by ion chromatography.

The literature review on the testing the chloride penetration resistance of concrete is published by Stanish et al. (1997).

Figure 3. Schematics of Ponding Tube Experimental Setup for Measuring the Transport of Chloride through the Concrete (Pesic, 2015)

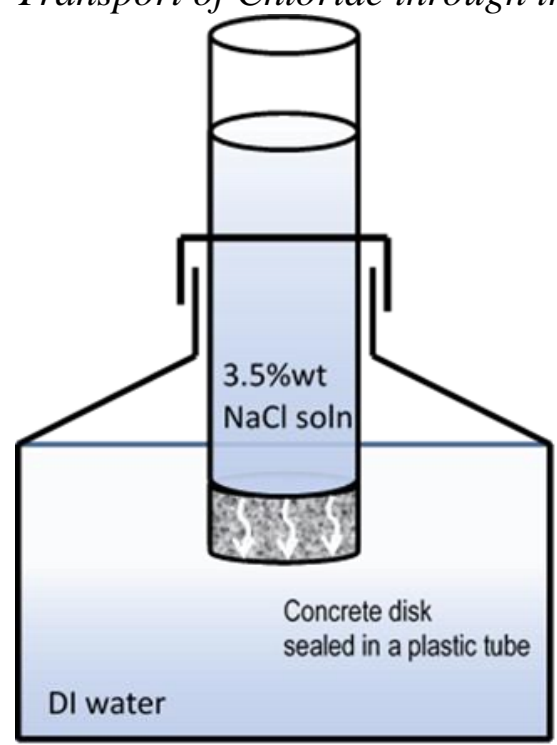

\section{$\underline{\text { Indirect Measurement Methods }}$}

Indirect permeability measurements are based on extent of corrosion of steel embedded in concrete. As all corrosion electrochemical studies require a three electrode system, in this work a unique approach was taken in such a way to also embed a port for accommodation of a reference electrode in the immediate proximity to the steel. This was done by using a glass tube during concrete casting, as presented in the Figure $4 \mathrm{a}-\mathrm{b}$. 
In this novel design the reference electrode does not need to be permanently embedded into concrete. Instead, a glass tube serving as a guide and accommodation of the reference electrode is permanently embedded in concrete. For this approach to work, the type of reference electrode is critical. The reference electrode must be of a small diameter $(2 \mathrm{~mm})$, and to be leakfree. Leak-free electrode means that the filling solution $(3 \mathrm{M} \mathrm{KCl})$ will not pass into the sample environment, thus preventing the contamination with chloride ions. Overall, the three electrode system consisted of a cylindrical rebar as a working electrode, mini silver-silver chloride electrode (used only during the measurements) and molybdenum wire coiled around the concrete cylinder as a counter electrode.

Figure 4a-b. (a)-Schematic Illustration of the Rebar Cylinder Electrode Embedded into Concrete (Pakharel, 2012). (b)- View of Actual Rebar Cylinder Embedded in Cured Concrete (After Halving for Illustration) and the Concrete Cylinder with Embedded Working Electrode and Glass Tube for Accommodation of Reference Electrode

(a)

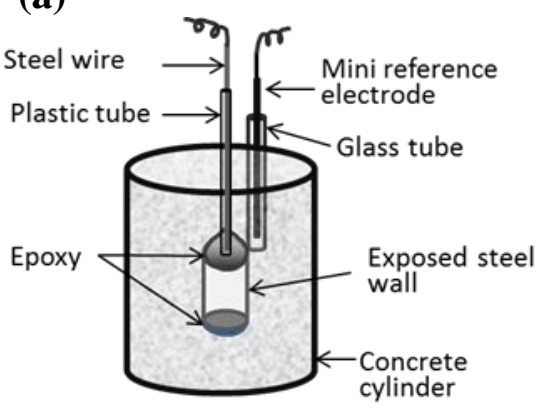

(b)

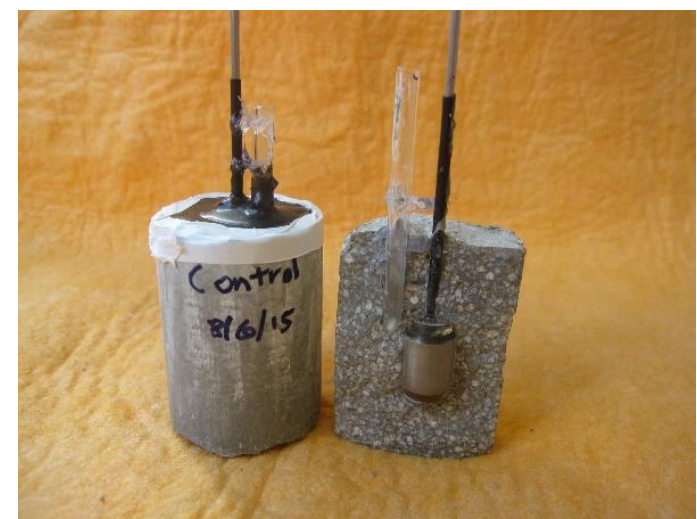

In this novel design the reference electrode does not need to be permanently embedded into concrete. Instead, a glass tube serving as a guide and accommodation of the reference electrode is permanently embedded in concrete. For this approach to work, the type of reference electrode is critical. The reference electrode must be of a small diameter $(2 \mathrm{~mm})$, and to be leakfree. Leak-free electrode means that the filling solution $(3 \mathrm{M} \mathrm{KCl})$ will not pass into the sample environment, thus preventing the contamination with chloride ions. Overall, the three electrode system consisted of a cylindrical rebar as working electrode, mini silver-silver chloride electrode (used only during the measurements) and molybdenum wire coiled around the concrete cylinder as a counter electrode.

The corrosion techniques used were open circuit potential, linear, Tafel and cyclic polarization. Electrochemical measurements are performed with EG\&G Potentiostat/Galvanostat, Model 273A, under computerized control by Soft-Corr 352 corrosion software. 
The rebar steel was acquired from Harris Rebar ABCO (2161 Lanark Street, Meridian, Idaho 838642) in 12mm diameter bars. The rebar was manufactured by Nucor Steel, Utah, with the composition is given below in Table 2.

Table 2. The Composition of Reinforcement Steel (Rebar)

\begin{tabular}{|l|l|l|l|l|l|l|l|l|l|l|l|}
\hline Comp. & $\mathrm{C}$ & $\mathrm{Mn}$ & $\mathrm{P}$ & $\mathrm{S}$ & $\mathrm{Si}$ & $\mathrm{Cu}$ & $\mathrm{Ni}$ & $\mathrm{Cr}$ & $\mathrm{Mo}$ & $\mathrm{V}$ & $\mathrm{Cb}$ \\
\hline$\%$ & 0.41 & 1.23 & 0.017 & 0.044 & 0.20 & 0.25 & 0.08 & 0.15 & 0.019 & 0.0029 & 0.001 \\
\hline
\end{tabular}

The bar was cut by two methods according to the type of electrode to be used. For cylindrical electrodes, about $25 \mathrm{~cm}$ length of a bar was machined out to remove the lugs. Afterward the individual cylinder samples were cut by machining to $13 \mathrm{~mm}$ lengths, and the ends machined out to smooth the surface roughness from cutting. The final dimensions were diameter $\mathrm{D}=12 \mathrm{~mm}$, and length $\mathrm{L}=12$ $\mathrm{mm}$.

\section{Results and Discussion}

Direct Measurement Methods

\section{Ponding Tube Method}

Figure 5. Effect of Aggregates and Aggregates Pretreatment on Permeability of Chloride in Concrete

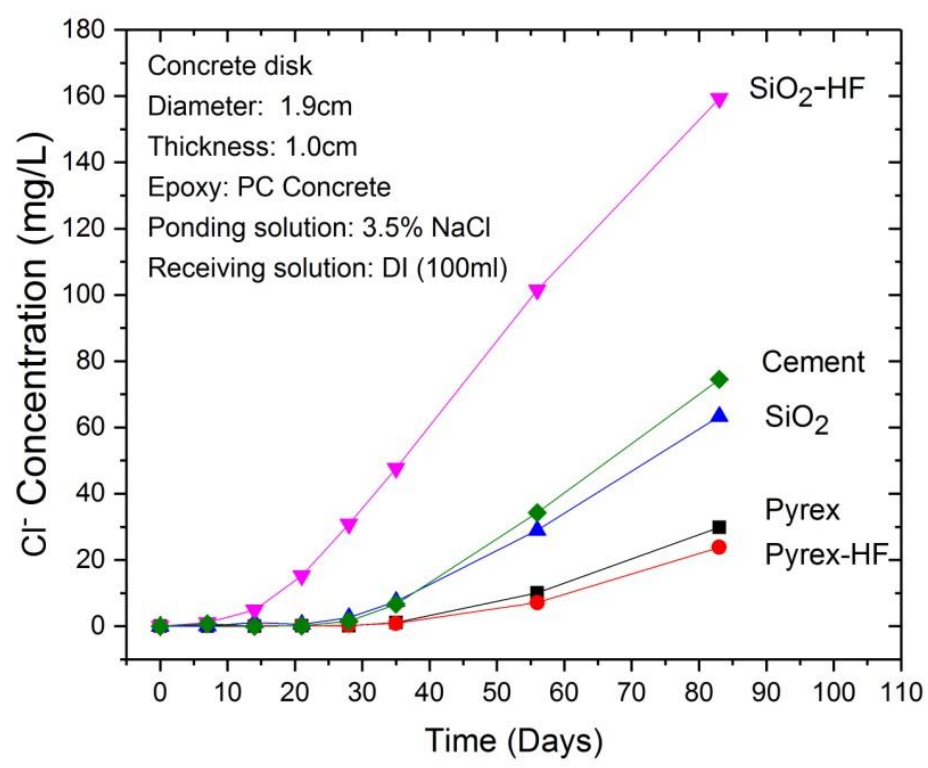

As presented in Figure 3 above, in this method the effect of admixtures or aggregates in concrete is studied by measuring the rate of chloride ion transport through the fixed $(1.0 \mathrm{~cm})$ concrete disk thickness and diameter $(1.9 \mathrm{~cm})$. The tube, filled with a $3.5 \% \mathrm{NaCl}$ solution, serves as the supplier of chloride ions. 
The deionized water in the jar serves as the receiver of chloride ions, which must transfer through the concrete disk in order to arrive there. Therefore, by measuring the chloride concentration with time, in the receiving water compartment, one can determine the rate of chloride transfer through the concrete. This method allows us to study the concrete transport properties as function of its composition with respect to admixtures, or aggregates.

For example, Figure 5 represents the effect of the silica based aggregates on the permeability of concrete, by using silica sand and crushed Pyrex glass. The reason for using Pyrex glass is to provide an abundant supply of the Si-O bonds for hydrogen bonding with water during curing of concrete. The additional curiosity was to examine the effect of etching, i.e. changing the surface properties, on concrete transport properties. Etching was done by using dilute hydrofluoric acid for several minutes, rinsing the aggregate with plenty of reverse osmosis water to remove the fluoride ions and prevent their introduction into the concrete matrix. The cured Portland cement served as the control. It can be seen that Pyrex, regardless of its pretreatment, produced the best results (the least permeability to chloride). On the other hand, the silica sand etched with HF caused very fast transport of chloride ions through the concrete structure. This experiment needs to be repeated to confirm the observed results.

Some of the experimental issues in this type of study are how to seal concrete disks to the plastic tube. If the concrete disk is sealed with an epoxy within the tube there are two interfaces that may provide the pathway for chloride ion diffusion. One interface would be the plastic wall-epoxy, and the other would be the epoxy-concrete side wall. To rule out the effect of plastic wall-epoxy interface the redesigned approach was to place the concrete disk outside the tip of the plastic tube and coat the side wall of concrete with special concrete epoxy, as done in this work. During the experiments only 3-4 mm of concrete disk is immersed in the water of receiving water compartment.

The pronounced effect of HF etching was also observed when round river rock (RR) pebbles was used as aggregates, Figure 6. Round river rock is a very hard material characterized with various surface chemistries dependent on the mineralogical composition. While the role of hydrofluoric acid etching is easier to determine, the role of crushing is not. What is not certain is which effect predominates during moisture and chloride ions transport, the fresh surface bonds enabling strong wetting, or the sharp and irregular shapes of the crashed material. The answer to this question will be provided in the additional research. 
Figure 6. Aggregate Surface Modification Effect on Permeability of Chloride in Concrete

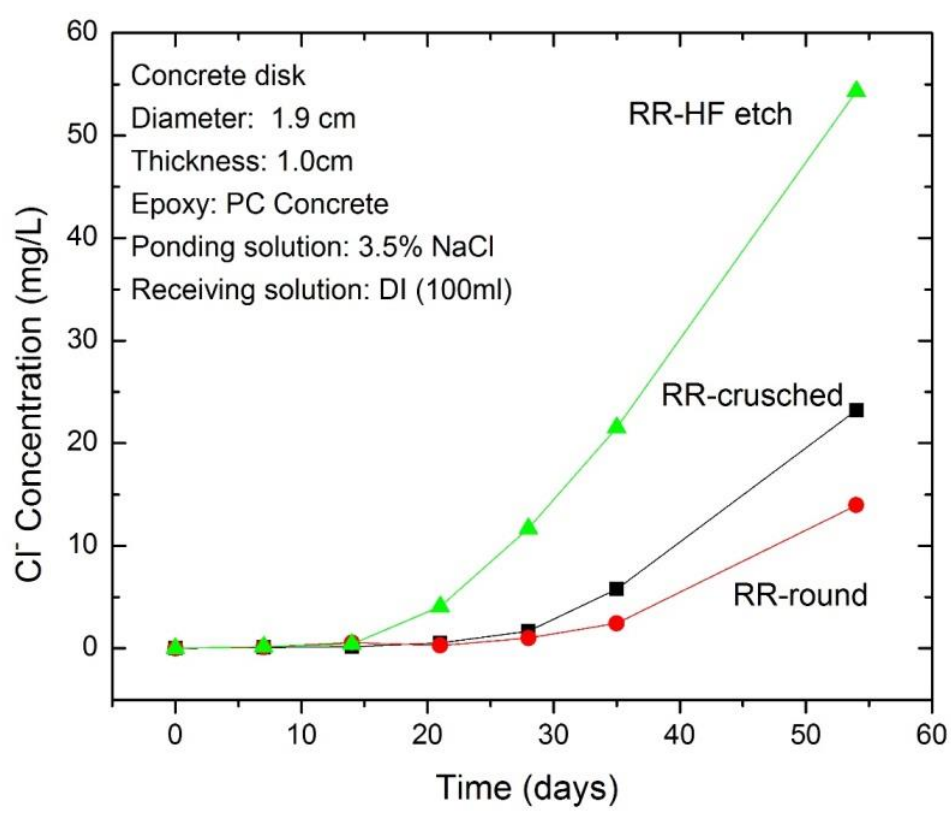

River Rock (RR) was Used as Aggregate

\section{Concrete Block, After Ponding, Analysis with Depth Method}

The permeability of concrete to chloride ions as a function of admixtures was determined by analyzing concrete with respect to chloride content with depth. Concrete blocks were prepared in a standard way (1:1, Portland cement: Aggregate weight ratio, with $40 \%$ wt water) but with addition of admixtures. The concentration effect of admixtures was studied with the $0.5,1.0$ and $2.0 \%$ wt of each. The admixtures were glycerol, micro silica, silica fume and colloidal silica. Upon curing for 28 days the blocks were placed in plastic boxes and flooded with $3.5 \% \mathrm{NaCl}$ solution. After about 565 days, the blocks were taken out, rinsed, dried and prepared for drilling to obtain the samples from particular depth in concrete. The blocks were drilled approximately every $7 \mathrm{~mm}$ till the center of block is reached. Exactly 1 gram of collected powder was dissolved in $100 \mathrm{ml}$ deionized water, filtered and analyzed for chloride by ion chromatography. Very good and consistent results were obtained.

According to the data in Figure 7, the addition of glycerol is very effective with respect to obstructing the chloride transport within concrete. The $0.5 \mathrm{wt} \%$ of glycerol was the most effective. 
Figure 7. Concentration Profile of Chloride Ion with Depth in Concrete Prepared by Using 0.5, 1.0 and 2.0 wt\% Glycerol. Solid Square Symbols Are the Control (Regular Concrete Block-No Admixture)

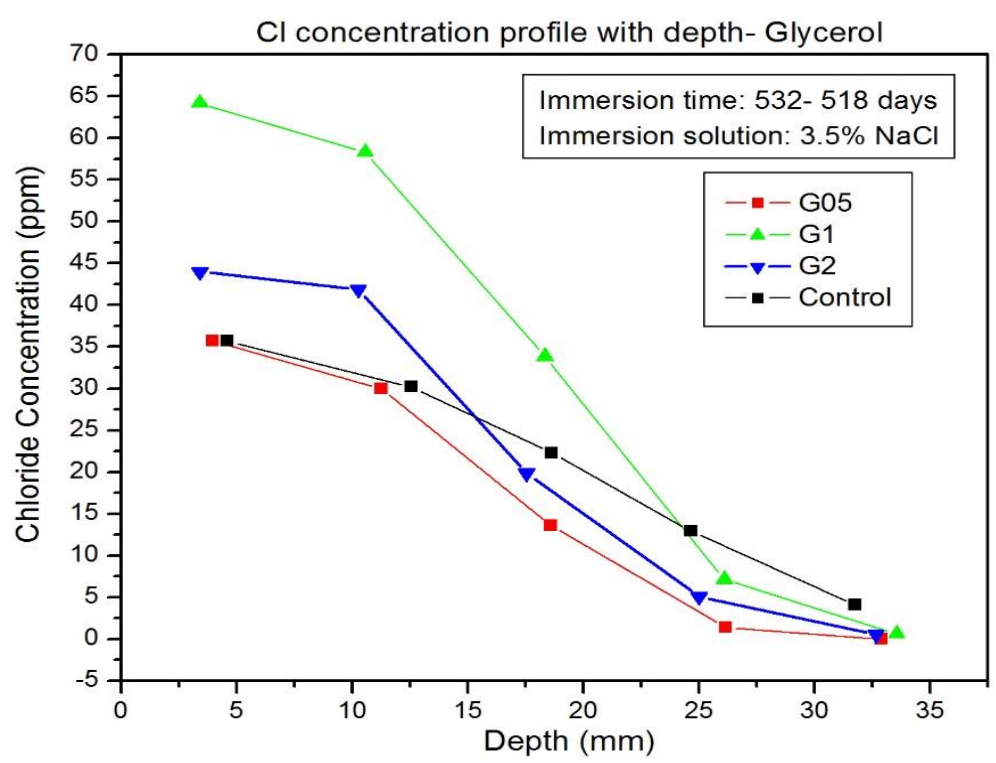

The use of silica admixtures proved to be detrimental to precluding the permeability of chloride ion in concrete. The results in Figure 8 show that colloidal and particularly micro silica increased considerably the permeability of chloride ions. Silica fume, not shown, had similar effect as micro silica.

Figure 8. Concentration Profile of Chloride Ion with Depth in Concrete Prepared by Using 0.5, 1.0 and 2.0 wt\% Micro Silica and Colloidal Silica. Solid Square Symbols are the Control (Regular Concrete Block).

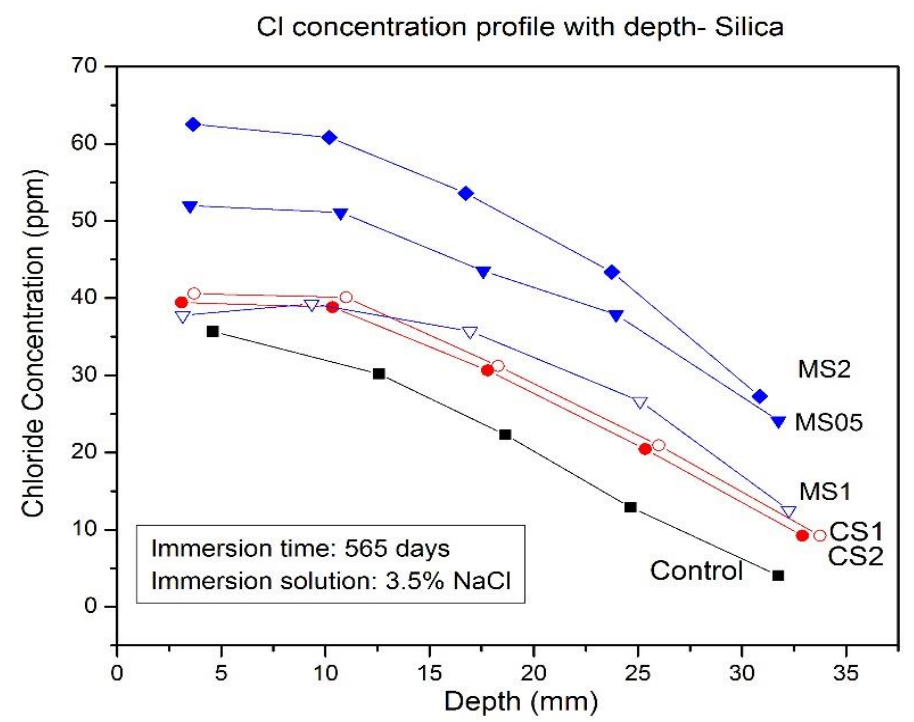




\section{Indirect Permeability Method - Corrosion of Reinforcement Steel}

As stated above, corrosion of reinforcement steel (rebar) in concrete could serve as the indicator on the presence of moisture and ions transported with it within the concrete structure. Therefore, this type of research took substantial time and effort to study the effect of various parameters, such as admixtures, on corrosion of rebar. The novelty of this research is that the reference electrode performs as if embedded permanently within the structure, see Figure 4 above.

The critical question that developed was if the above described experimental setup would work at all. The perception that it should not work because there was no electrolyte within the concrete to provide a conduit for charge transfer during the corrosion and to enable the measurement of a voltage difference between the working and the reference electrode. However, when all three electrodes were connected to a potentiostat, and one of the standard polarization techniques was tried, it was surprisingly discovered that the voltage-current relationship was clearly established. From this point on, it was decided to explore the corrosion of steel embedded in concrete by using standardized corrosion techniques, such as linear, Tafel and cyclic polarization, as if the steel is immersed in an electrolyte. This development opened opportunities to study the properties of concrete as a function of many parameters, its composition, microstructure, the presence of admixtures and aggregates, and the environmental conditions.

It is not known exactly why it was possible to establish the voltage-current relationship but one proposition is the design of reference electrode. The reference electrode is a plastic (PEEK) barrel filled with $3 \mathrm{M} \mathrm{KCl}$ solution into which an anodized $\mathrm{Ag} / \mathrm{AgCl}$ wire is immersed. Thus far nothing extraordinary is present here. However, the end of reference electrode is closed (to prevent the leakage of $3 \mathrm{M} \mathrm{KCl}$ electrolyte) with a proprietary ionically conductive resin (Innovative Instruments, Inc., Tampa, FL, USA). The resin must have been so sensitive that even a minimal amount of moisture absorbed and bound by concrete is sufficient to establish the voltage difference against the nearby steel sample. Once this difference is established then the potentiostat can be programmed to impose potentials against the reference electrode potential and monitor the resulting current flowing (corrosion) between the working and counter electrodes. In Figure 9a-b below, just for the illustration/verification purpose, the results from linear and Tafel polarization are presented. Figure $9 \mathrm{~b}$ shows the effect of glycerol admixture on rebar corrosion as measured by Tafel polarization. Overall, from numerous experiments performed thus far, it was found that the corrosion of rebar embedded in concrete is not sensitive enough for studies on concrete permeability to moisture and chloride ions. 
Figure 9a-b. Electrochemical Polarization of Reinforcement Steel Embedded in Concrete by Using the Reference Electrode next to the Working Electrode. Concrete, Prepared by Addition of Glycerol, Together with Embedded Electrodes is Immersed in 3.5\% NaCl Solution. (a) Linear Polarization; (b) Tafel Polarization of Reinforcement Steel as a Function of Glycerol Admixture

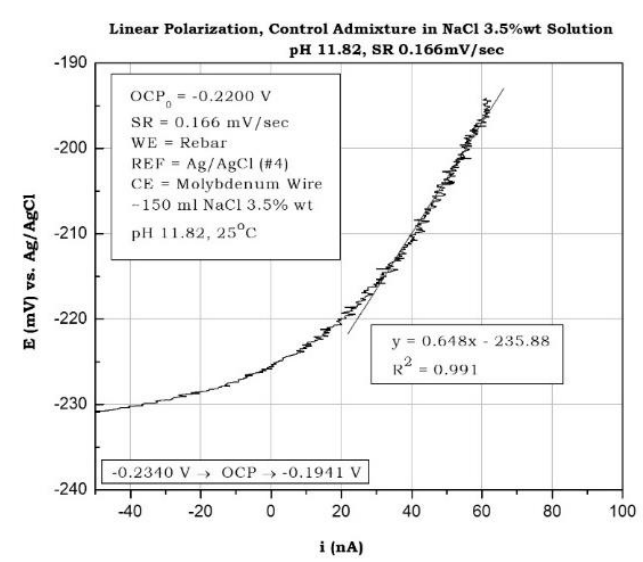

(a)

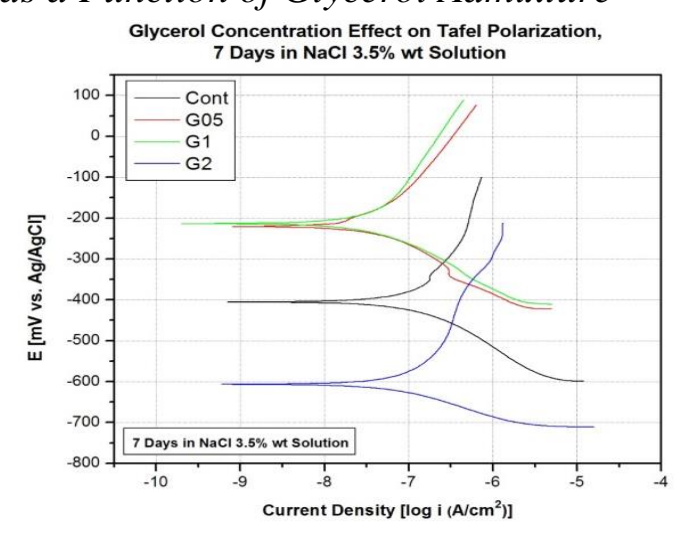

(b)

\section{Conclusions}

Two methods were used to determine permeability of concrete to moisture and chloride ions. These are direct concentration of chloride measurement methods and an indirect method based on corrosion of reinforcement steel.

The concrete sealed and ponded in a tube method is a new approach for characterization of concrete properties with regard to permeability to chloride.

Both, the tube method and the analysis of concrete with depth method showed that the use of glycerol as an admixture had a positive effect on reducing the permeability of chloride ions. Silica based admixtures as nanofillers of pores in concrete had a negative effect, i.e. these admixtures enhanced the permeability of concrete.

The new design for accommodation of reference electrode proved to be very beneficial for corrosion of reinforcement steel studies. This kind of design was not reported by other labs before. Although the new design for accommodation of reference electrode is beneficial for the corrosion of reinforcement steel studies it is not sensitive enough for the characterization of concrete with respect to its permeability to moisture and chloride ions.

\section{Acknowledgments}

The funding for this report by the US Department of Energy, via Nuclear Engineering University Programs (NEUP), is fully acknowledged. The author also thanks Robert Miner and Robert Blair, undergraduate students in the department, for preparing some of the concrete samples. 


\section{References}

Aggarwal, P., Singh, R. \& Aggarwal, Y., 2015. Use of nano-silica in cement based materials- A review. (http://dx.doi./10.1080/23311916.2015.1078018), Cogeng Engineering, pp. 2-11.

Bentz, D., Snyder, K., Cass, L. \& Peltz, M., 2008. Doubling the service life of conctrete structures. I: Reducing ion mobility using nanoscale viscosity modifiers. Cement \& Concrete Composites, 30, pp. 674-678.

Bentz, D., Peltz, M., Snyder, K. \& Davis, J., 2009. Verdict: Viscosity enhancers reducing diffusion in concrete technology. Concrete International, Issue January, pp. 31-36.

Bentz, D., Snyder, K. \& Peltz, M., 2010. Doubling the service life of concrete structures. II: Performance of nanoscale viscosity modifiers in mortars. Cement \& Concrete Composites, 32, pp. 187-193.

Bentz, D. P.; Zunino, F.; Lootens, D. 2016. Chemial vs. Physical acceleration of cement hydration, Concrete International, 38 (11), pp.37-44.

Bullard, J. W.; Jennings, H. M.; Livingston, R. A.; Nonat, A.; Scherer, J. W.; Schweitzer, J. S.; Scrivener, K. L.; Thomas, J. J. 2011. Mechanisms of cement hydration, Cement and Concrete Research, 41, pp. 1208-1223.

Chala, R.; R. M. 2015. Experimental study of temperature rise and early age thermal crack control in concrete, International Journal of Research in Engineering and Technology, 4(7), pp. 197-202.

Cortas, R.; Rozière, E.; Staquet, S.; Hamami, A.; Loukili, A.; Delplancke-Ogletree, M.-P. 2014. Effect of the water saturation of aggregates on the shrinkage induced cracking risk of concrete at early age, Cement \& Concrete Composites, 50, pp. 1-4.

Ganesh, P. et al., 2016. Effect of nanosilica on durability and mechanical properties of high-strength concrete. Magazine of Concrete Research, 68(5), pp. pp. 229-236.

Hansson, C. M.; Poursaee, A.; Jaffer, S. J. December 2012. Corrosion of reinforcing bars in concrete, The Masterbuilder, pp. 106-124.

Lee, M. K.; Jung, S. H.; Oh, B. H. 2013. Effects of carbonation on chloride penetration in concrete, ACI Materials Journal, September-October, pp. 559-566.

Liu, W.; Cao, W.; Yan, H.; Ye, T.; Jia, W. 2016. Experimental and Numerical Studies of Controlling Thermal Cracks in Mass Concrete Foundation by Circulating Water, Applied Sciences, 6 (110), pp. 1-18.

Magniont, C., Escadeillas, G., Oms-Multon, C. \& De Caro, P., 2010. The benefits of incorporating glycerol carbonate into an innovative pozzolanic matrix. Cement and Concrete Research, 40, pp. 1072-1080.

Pesic, B., 2014. Doubling the life of concrete structures, Report to Nueclear Engineering University Programs (NEUP), Grant No. DE-NE0000659, February 1-September 30, 2014, US Department of Energy.

Pesic, B., 2015. Doubling the life of concrete structures, Report to Nueclear Engineering University Programs (NEUP), Grant No. DE-NE0000659, April 1-June, 30, 2015. US Department of Energy.

Pokharel, K., 2012. Effects of sodium citrate on corrosion ihibition of TMT rebar to chloride contaminated envrionment (Master's Thesis, University of Idaho, USA).

Singh, L. et al., 2013. Beneficial role of nanosilica in cement based materials- A review. Construction and Building Materials, 47, pp. 1069-1077.

Skripkiūnas, G.; Nagrockienė, D.; Girskas, G.; Vaičienė, M.; Baranauskaitė, E. 2013. The Cement Type Effect on Freeze - Thaw and Deicing Salt Resistance of Concrete. Procedia Engineering, 57 (2013), pp. 1045-1051. 
Stanish, K., Hooton, R. \& Thomas, M., 1997. Testing the chloride penetration resistance of concrete: A literature review, Report - FHWA Conract DTFH61-97-R-00022, University of Toronto, Toronto, CA.

Stark, J., 2011. Recent advances in the field of cement hydation and microstructure analysis. Cement and Concrete Research, 41, pp. 666-678. 